Disclosure of Interests: None declared

DOI: 10.1136/annrheumdis-2019-eular.6610

\section{AB0571 BENEFICIAL EFFECTS OF VACCINATION ON REDUCING RISKS OF INFLUENZA INFECTION IN PATIENTS WITH SYSTEMIC LUPUS ERYTHEMATOSUS}

Jinquan $\mathrm{Yu}^{1}$, Dandan $\mathrm{Xu}^{2}$. 'Distinct HealthCare, Department of Rheumatology, Shenzhen, China; ${ }^{2}$ Shenzhen Sixth People's Hospital (Nanshan Hospital), Nephrology department, Shenzhen, China

Background: In patients with systemic lupus erythematosus (SLE), infection is a major cause of morbidity and mortality. Influenza is one of the most common infectious diseases which can be prevented in a certain degree by vaccination, while in fact, influenza vaccination rates of SLE are really low in China.

Objectives: To investigate the influenza vaccination rate of SLE patients and the reasons for nonadherence to vaccination. To evaluate beneficia effects and safety of influenza vaccination.

Methods: A cross section study was performed among patients with SLE regular follow-up in Distinct HealthCare between June 1 and November 31. Vaccination status and influenza infection condition were surveyed Demographic information, clinical features and laboratory characters were collected and systemic lupus erythematosus disease activity index (SLEDAI) was documented.

Results: 109 SLE patients were recruited, including 42 immunized with trivalent or quadrivalent split virion influenza vaccine and 67 non-vaccinated. There were no significant differences in demographic and clinical characteristics $(p>0.05)$. The influenza vaccination rate was $38.5 \%$. Influenza infection rates in the vaccinated and non-vaccinated were $7.1 \%(3 /$ $42)$ and $23.9 \%(16 / 67)$, respectively, with statistic difference $(p<0.05)$ Reasons that non-vaccinated patients reported for nonadherence included refused by the community health workers due to basic disease of SLE $(32.3 \%)$, vaccine shortages $(27.7 \%)$, concerns for potential side effects $(23.1 \%)$ and insufficient patient education (16.9\%). No systemic adverse reactions were observed and no significant increase of disease activity was found in vaccinated patients.

Conclusion: - 1. Split virion influenza vaccine is effective in reducing risks of influenza infection in patients with SLE, and also safe.

- 2. Influenza vaccination is insufficient in SLE patients.

- 3. Education of the community health workers and patients is important to increase influenza vaccination rate.

\section{REFERENCES}

[1] Belongia EA, Skowronski DM, McLean HQ, et al. Repeated annual influenza vaccination and vaccine effectiveness: review of evidence. Expert Rev Vaccines. $2017 \mathrm{Jul} ; 16(7): 1-14$

[2] Baillet A, Gossec L, Carmona L, et al. Points to consider for reporting, screening for and preventing selected comorbidities in chronic inflammatory rheumatic diseases in daily practice: a EULAR initiative. Ann Rheum Dis. 2016 Jun;75(6):965-73.

[3] Chang CC, Chang YS, Chen WS, et al. Effects of annual influenza vaccination on morbidity and mortality in patients with Systemic Lupus Erythematosus: A Nationwide Cohort Study. Sci Rep. 2016 Dec 2;6:37817.

[4] Lawson EF, Trupin L, Yelin EH, et al. Reasons for failure to receive pneumococcal and influenza vaccinations among immunosuppressed patients with systemic lupus erythematosus. Semin Arthritis Rheum. 2015 Jun;44 (6):666-71

[5] Murdaca G, Orsi A, Spanò F, et al. Influenza and pneumococcal vaccinations of patients with systemic lupus erythematosus: current views upon safety and immunogenicity. Autoimmun Rev. 2014 Feb;13(2):75-84.

Disclosure of Interests: None declared

DOI: 10.1136/annrheumdis-2019-eular.2756

\section{AB0572 INVASIVE MYCOSES IN PATIENTS WITH CONNECTIVE TISSUE DISEASE FROM SOUTHERN CHINA: CLINICAL FEATURES AND ASSOCIATED FACTORS}

Dongying Chen ${ }^{1}$, zhongping zhan ${ }^{2}$. ${ }^{1}$ The first affiliated hospital of sun yat-san university, rheumatology, Guangzhou, China; ${ }^{2}$ first affiliated hospital of sun yat-san university, rheumatology, Guangzhou, China

Background: Invasive fungal disease (IFD) was well studied in patients with AIDS and organ transplant recipients. A few researches illustrated that patients with connective tissue disease (CTD) were also predisposed to IFD. However, few researches were designed to focus on invasive mycosis (IM) in patients with CTD.

Objectives: To investigate the clinical features and associated factors of IM in patients with CTD from Southern China.

Methods: A retrospective study CTD was performed. Demographic and clinical data were recorded. Associated factors were analyzed by logistic regression analysis.

Results: A total of 32 patients with CTD were included. The incidence of IM was $0.5 \%$ in patients with CTD $(32 / 6911)$ and the highest in patients with ANCA-associated vasculitis (AAV) $(7 / 480,1.5 \%)$. Molds were isolated in 20 sputum specimens (20/29, 69.0\%). Aspergillus spp. (81.3\%) were the leading strain. Positivity of serum G-test and GM-test was $47.8 \%(11$ 23) and $34.6 \%(9 / 26)$, respectively. GM-test was positive in BALF from seven patients. Lung was commonly involved (30/32, 93.8\%). Pulmonary nodules $(46.7 \%)$ and cavitary lesions $(36.7 \%)$ were common. Ten patients died $(31.3 \%)$, including three with AAV $(42.9 \%)$ and seven with SLE $(36.8 \%)$. Multivariate logistic regression analysis showed that lymphopenia [odds ratio $(\mathrm{OR})=3.28,95 \%$ confidential interval $(\mathrm{Cl})$ 1.29-8.38, $P=0.01$ ] and median-to-high dose of glucocorticoid (GC) [OR=3.40, 95\% Cl 1.04 11.13, $P=0.04$ ] was associated with $\mathrm{IM}$ in patients with CTD. Patients with lymphopenia experienced higher risk of co-infection $(50.0 \%$ vs $0 \%$, $P=0.01)$ and mortality $(45.5 \%$ vs $0 \%, P=0.01)$ compared with patients with normal lymphocyte count.

Conclusion: IM tended to develop in patients with AAV, resulting in high mortality. Sputum culture could be an effective and non-invasive method to diagnose IM. Lymphopenia, and median-to-high dose of GC are asso ciated with IM in patients with CTD.

Acknowledgement: no

Disclosure of Interests: None declared

DOI: 10.1136/annrheumdis-2019-eular.982

\section{Vasculitis}

\section{AB0573 ASSESSMENT OF PRESENCE, SEVERITY AND RISK FACTORS OF POST- THROMBOTIC SYNDROME IN VASCULAR BEHÇET DISEASE: MUTICENTERED RETROSPECTIVE STUDY}

Aysun Aksoy ${ }^{1,2}$, Seda Colak ${ }^{3}$, Ahmet Omma ${ }^{4}$, Burcu Yağız $z^{5}$, Belkis Nihan Seniz ${ }^{5}$, Naile Bolca ${ }^{6}$, Rabia Ergelen ${ }^{7}$, Haner Direskeneli ${ }^{2}$, Fatma Alibaz-Oner ${ }^{2}{ }^{1}$ University of Manchester, Manchester, United Kingdom: ${ }^{2}$ Marmara University School of Medicine, Internal Medicine, Division of Rheumatology, istanbul, Turkey; ${ }^{3}$ Gülhane Education and Training Hospital, Internal Medicine, Division of Rheumatology, istanbul, Turkey; ${ }^{4}$ Ankara Numune Training and Research Hospital, ankara, Turkey, ${ }^{5}$ Uludag university School of Medicine, Internal Medicine, Division of Rheumatology, Bursa, Turkey; ${ }^{6}$ Uludag university School of Medicine, Division of Radiology, istanbul, Turkey, ${ }^{7}$ Marmara University School of Medicine, Division of Radiology, istanbul, Turkey

Background: DVT(deep venous thrombosis) is the most common form of vascular Behçet Disease(VBD).Post-trombotic syndrome(PTS) developing after a thrombotic event in lower extremity is the most important complication of DVT and affects negatively patients' quality of life.

Objectives: We aimed to assess presence,severity and risk factors of $\mathrm{PtS}$ and venous disease spesific quality of life in VBD

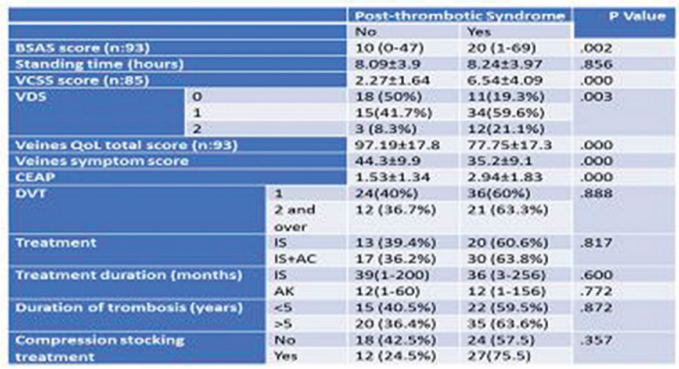

Methods: This study included 96 BD patients (Female/Male:18/78,mean age: $38.8 \pm 8.74$ )with DVT from 3 tertiary Rheumatology centers in Turkey. When vascular involvement developed, mean age was $32.7 \pm 8.65$ (female: 35.4 \pm 10.7 ; male: $32.09 \pm 8 ; p>.005$ ) Villalta scale is used to assess PTS and according to scale; PTS is present if score $>4$ and degree of PTS mild, moderate and severe if score $5-9,10-14,>14$ respectively. The Venous Disability Score(VDS) and the Venous Clinical Severity Score 